Recepción: 07 / 11 / 2016

Aceptación: 15 / 03 / 2017

Publicación: 29 / 04 / 2017

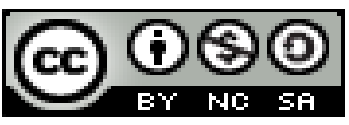

Ciencias de la salud Artículo de investigación

\title{
Caries dental en el embarazo
}

\section{Dental Caries in Pregnancy}

\section{Cárie dentária na gravidez.}

\author{
Juan A. Oliveira-del Rio \\ juanoliveiradelrio@hotmail.com \\ José P. MuñozCruzatty ${ }^{I I}$ \\ jose.munoz@uleam.edu.ec \\ Evelyn M. Tovar-Moreira ${ }^{\mathrm{III}}$ \\ evelyn.tovar@uleam.edu.ec
}

Correspondencia: juanoliveiradelrio@hotmail.com

\footnotetext{
${ }^{\text {I }}$ Magister Scientiarum en Odontopediatria, Odontólogo, Docente de la Universidad Laica Eloy Alfaro de Manabí, Manta, Ecuador.
}

${ }^{\text {II }}$ Magister en Gerencia y Auditoria de Servicios de Salud Bucal, Doctor en Odontología, Diplomado Superior en Odontología Integral, Docente de la Universidad Laica Eloy Alfaro de Manabí, Manta, Ecuador.

\footnotetext{
${ }^{\text {III }}$ Magister en Gerencia Y Auditoria de Servicios de Salud Bucal, Especialista en Odontología Infantil, Doctor en Odontología, Docente de la Universidad Laica Eloy Alfaro de Manabí, Manta, Ecuador.
} 


\section{Resumen}

Se realizó un estudio descriptivo transversal en la consulta privada, con vistas a determinar la presencia de caries dental, y otros factores de riesgo asociados en el primer y tercer trimestre del embarazo. La población de estudio (50 embarazadas dispensarizadas) arrojó en el primer trimestre los 80,95\% de embarazadas afectadas por caries dental, y en el tercer trimestre el 66,0 $\%$ de ellas lograron eliminarlas; se detectó la aparición de lesiones cariosas nuevas en catorce mujeres $(28,0 \%)$. Se concluyó, que el embarazo genera adaptaciones en la fisiología femenina, lo cual repercute en la salud bucal de la gestante, siendo las más frecuentes la caries dental, lo que puede afectar la salud bucal y general del futuro bebé, de ahí la importancia de tener en cuenta en el período prenatal la prevención de esta enfermedad.

Palabras clave: embarazada, caries dental, factores de riesgo.

\section{Abstract}

A cross - sectional descriptive study was carried out in the private practice, in order to determine the presence of dental caries, and other associated risk factors in the first and third trimesters of pregnancy. The study population (50 pregnant women dispensed) in the first trimester showed $80.95 \%$ of pregnant women affected by dental caries, and in the third quarter $66.0 \%$ of them were able to eliminate them; The occurrence of new carious lesions was detected in 14 women $(28.0 \%)$. It was concluded that pregnancy generates adaptations in the female physiology, which affects the oral health of the pregnant woman, being the most frequent dental caries, which can affect the oral and general health of the future baby, hence the importance of Take into account in the prenatal period the prevention of this disease.

Key words: pregnant, dental caries, risk factors.

\section{Resumo}

Um estudo descritivo transversal na prática privada, a fim de determinar a presença de cáries dentárias, e outros factores de risco associados, no primeiro e terceiro trimestre da gravidez foi realizada. A população do estudo (50 dispensarizadas grávidas) postou no primeiro trimestre, $80,95 \%$ das mulheres grávidas afetados por cáries, e no terceiro trimestre $66,0 \%$ deles foram 
capazes de eliminá-los; o aparecimento de novas lesões de cárie foram detectados em catorze mulheres $(28,0 \%)$. Concluiu-se que a gravidez produz adaptações na fisiologia feminina, que afeta a saúde bucal de gestantes, a cárie dentária mais frequente, o que pode afetar a saúde bucal e geral do bebê, daí a importância de considerar pré-natal prevenir esta doença.

Palavras chave: grávidas, cárie dentária, factores de risco.

\section{Introducción}

Desde épocas muy remotas existen evidencias de la presencia de caries dental en humanos, estas se remontan hasta la era del Neandertal, en cuyos cráneos se encontró esta como un hallazgo relevante. ${ }^{1}$

La definición de caries dental ha sido enfocada de diferentes modos: desde el punto de vista morfológico, es una enfermedad que determina la destrucción de la estructura del diente. Según los criterios epidemiológicos es la enfermedad con mayor prevalencia que padece el hombre moderno. Desde la perspectiva sociológica, es una enfermedad biosocial, dependiente de la calidad y condiciones de vida de un determinado grupo poblacional; para otros es una enfermedad infecciosa. ${ }^{1}$

La salud materno-infantil en sus distintos períodos, con énfasis en el período prenatal, es hoy día uno de los temas más relevantes para la sociedad a nivel internacional. Un embarazo saludable y un parto seguro son los cimientos esenciales para una vida feliz y productiva. ${ }^{2}$

La gestación genera adaptaciones en la fisiología femenina que obligan al odontólogo a ampliar sus conocimientos y habilidades en relación con el proceso reproductivo y la atención odontológica en este período. ${ }^{2}$ Los cambios en el embarazo pueden predisponer al desarrollo de caries al aumentar los recuentos de bacterias cariogénicas, y aumentar el riesgo de infección de sus hijos, con el consecuente riesgo de desarrollar caries.

La susceptibilidad a caries dental en el embarazo puede aumentar debido a factores como el aumento de la cantidad de Streptococus mutans y lactobacilos ácidofilos, a la ingestión más frecuente de carbohidratos y a la mayor ocurrencia de vómitos, junto a un desequilibrio del pH de la saliva. Además de estos factores de riesgo referidos aparecen referencias de otros ${ }^{6}$, el embarazo 
previo, el que se ha sugerido pudiera elevar la severidad de las enfermedades bucales que afectan a la mujer durante la gestación. ${ }^{3}$

Los cambios hormonales, salivales, microbiológicos e inmunológicos referidos por varios investigadores, constituyeron factores que aumentaron el riesgo de padecer estas enfermedades. También describieron que los cambios desfavorables en la saliva se correspondieron con el aumento de la caries durante el embarazo. Sin embargo, estos autores no dispusieron de información concluyente que permitiera cerrar la página de la investigación científica al respecto. $^{4}$

La elevada prevalencia de caries dental en las mujeres embarazadas, incluso en aquellas que antes del periodo gestacional han presentado una salud bucal buena, unida a la difundida creencia de que el embarazo provoca caries dental y afecta la salud bucal, motivó a realizar esta investigación.

\section{Material y método}

Se realizó un estudio descriptivo transversal en la consulta privada. La población estudio estuvo conformada por 50 embarazadas dispensarizadas, con vistas a determinar la presencia de caries dental y algunos factores de riesgo asociados en el primer y tercer trimestres del embarazo.

Cada embarazada fue sometida a interrogatorio y examen bucal en el primer y tercer trimestres de la gestación. Se les llenó un formulario con los datos generales e información referida a la afectación por caries dental y a algunos factores de riesgo asociados a la enfermedad, con el objetivo de constatar posibles cambios en el transcurso del embarazo. Los factores de riesgo seleccionados para el estudio se basaron en la revisión bibliográfica realizada y se incluyeron los más frecuentemente asociados a la enfermedad cariosa en el periodo gestacional y factibles de ser medidos en el contexto objeto de estudio. Los factores de riesgo a caries dental que se consideraron fueron: higiene bucal, dieta cariogénica, $\mathrm{pH}$ salival, vómitos y embarazo previo.

La higiene bucal se midió por el índice de higiene bucal de Love y se consideró higiene bucal buena para valores de $20 \%$ o menos y deficiente por encima del $20 \%$. La dieta cariogénica fue definida en el interrogatorio teniendo como referencia la descripción de la ingesta de alimentos durante las últimas 24 horas. Se definió dieta cariogénica si se refería a consumo de alimento azucarados en cuatro momentos del día. ${ }^{6,7}$ 
El pH salival se determinó con un peachímetro digital modelo metrohm c-32. La muestra de saliva para la determinación del pH se obtuvo mediante la recolección de la misma en un tubo de ensayo. Se consideró pH salival bajo al valor menor de 6,5 según la curva de Stephan ${ }^{5}$ 7. Se consideraron factores de riesgo presentes la higiene bucal deficiente, el consumo de dieta cariogénica, el pH salival bajo, la ocurrencia de vómitos y la experiencia de embarazo previo.

\section{Resultados y discusión}

Uno de los principales problemas durante el embarazo es la caries dental. Es, posiblemente, una de las creencias más comentadas en referencia al embarazo y salud oral. En la tabla 1 se observa que en el primer trimestre, el 80,0 \% de las embarazadas estaban afectadas por caries dental, y en el tercer trimestre el 66,0 \% lograron eliminarlas; se detectó la aparición de lesiones cariosas nuevas en catorce mujeres, lo que representó el 28,0 \%.

Tabla 1. Distribución de embarazadas afectadas y no afectadas por caries dental en el primer $y$ tercer trimestres

\begin{tabular}{|l|l|l|l|l|}
\hline \multirow{2}{*}{$\begin{array}{l}\text { Afectación por } \\
\text { caris dental }\end{array}$} & \multicolumn{2}{|c|}{ Primer trimestre } & \multicolumn{2}{c|}{ Tercer trimestre } \\
\cline { 2 - 5 } & No & $\%$ & No & $\%$ \\
\hline Afectadas & 40 & 80 & 14 & 28 \\
\hline No afectadas & 10 & 20 & 26 & 52 \\
\hline
\end{tabular}

La caries dental se reporta como una de las enfermedades que más afecta a la población mundial, y especialmente a las mujeres durante el embarazo ${ }^{8,9}$. El bajo porcentaje de embarazadas afectadas para el tercer trimestre en el estudio pudo deberse a la labor preventivo-curativa realizada a las embarazadas, como parte de la atención odontológica a este grupo, aunque aparecieron caries dentales en catorce mujeres durante el embarazo, lo que obliga a reforzar las medidas de promoción y prevención. ${ }^{10}$

\section{4}

Pol. Con. (Edición núm. 6) Vol. 2, No 4, abril 2017, pp. 80-91, ISSN: 2550 - 682X 
El conocimiento del riesgo de padecer de caries dental durante el periodo de embarazo es esencial para un correcto plan de tratamiento con las acciones educativas y preventivas, necesarias para que las madres puedan cuidar adecuadamente de su salud bucal y la de sus hijos. ${ }^{11}$

Algunas investigaciones permiten deducir que el aumento de las lesiones cariosas de las embarazadas se debe a un incremento de los factores cario génicos locales, entre los que se encuentran: cambios de la composición de la saliva y la flora bucal, vómitos por reflujo, higiene deficiente y cambios en los hábitos dietéticos. ${ }^{2}$

La OMS define que un factor de riesgo es cualquier rasgo, característica o exposición de un individuo que aumente su probabilidad de sufrir una enfermedad o lesión. Entre los factores de riesgo más importantes cabe citar la insuficiencia ponderal, las prácticas sexuales de riesgo, la hipertensión, el consumo de tabaco y alcohol, el agua insalubre, las deficiencias del saneamiento y la falta de higiene. ${ }^{12}$

En la tabla 2 se pueden apreciar los factores de riesgo que se presentaron con mayor frecuencia en las embarazadas en el primer trimestre de gestación: ingestión de alimentos azucarados con un $90,0 \%$, y la higiene bucal deficiente en cuarenta pacientes para un 80,0 \%. La labor de promoción y prevención realizada por el personal del equipo de salud logró modificar la higiene bucal deficiente a quince embarazadas en el tercer trimestre, diez lograron tomar todas las medidas en el momento de la ingestión de alimentos azucarados. 
Tabla 2. Distribución de los factores de riesgos presentes en el primer y tercer trimestre de embarazo

\begin{tabular}{|c|c|c|c|c|}
\hline \multirow{2}{*}{$\begin{array}{c}\text { Factores de } \\
\text { riesgo }\end{array}$} & \multicolumn{2}{|c|}{ Primer trimestre } & \multicolumn{2}{|c|}{ Tercer trimestre } \\
\hline & No & $\%$ & No & $\%$ \\
\hline $\begin{array}{l}\text { Higiene bucal } \\
\text { deficiente }\end{array}$ & 40 & 80 & 25 & 50 \\
\hline $\begin{array}{l}\text { Ingestión de } \\
\text { alimentos } \\
\text { azucarados }\end{array}$ & 45 & 90 & 35 & 70 \\
\hline $\mathrm{Ph}$ saliva bajo & 10 & 18 & 3 & 6.0 \\
\hline Vómito & 30 & 60 & 4 & 8.0 \\
\hline $\begin{array}{c}\text { Embarazo } \\
\text { previo }\end{array}$ & 10 & 20 & 10 & 20 \\
\hline
\end{tabular}

El embarazo previo se presentó en diez embarazadas del total examinado, y constituyó el 20,0 \%. En relación con la ocurrencia de vómitos y el pH salival bajo, ambos factores de riesgo se modificaron entre el primer y tercer trimestre. En el primer trimestre, treinta mujeres refirieron ocurrencia de vómitos, y en cuatro de ellas persistió este factor de riesgo para el tercer trimestre. El pH salival se elevó en el transcurso del embarazo en tres de las diez mujeres que presentaron este factor de riesgo al inicio de la gestación.

Estudios realizados por Pérez Oviedo ${ }^{10}$ y colaboradores sobre los factores de riesgo, coinciden con nuestro estudio en relación con la disminución de la higiene bucal deficiente, no así en la ingestión de alimentos azucarados (dieta criogénicas). 
Otro estudio realzado por Noguera Planas M. con el objetivo de describir los factores de riesgo en la caries dental, se observó que la mala higiene bucal y la ingestión de alimentos azucarados de forma abundante fueron los que más se relacionaron con la presencia de la enfermedad. ${ }^{1}$

La dieta cariogénica constituye uno de los factores de riesgo más frecuentes asociados a la caries dental, y está relacionada con los cambios en el estilo de vida de la mujer gestante; la que muestra gran apetencia por los dulces y mayor ingestión de estos ${ }^{13-15}$. Por otro lado, la higiene bucal deficiente propicia la acumulación de placa dentobacteriana, lo cual reduce el coeficiente de difusión de los ácidos formados por los microorganismos, facilita la desmineralización y eleva el riesgo a caries dental. La dieta pone a disposición de los microorganismos de la placa dentobacteriana el sustrato metabólico, lo que sumado a los malos hábitos de higiene bucal pueden dar lugar a un aumento de la incidencia de caries dental en el embarazo, sin que sea necesaria, además, la existencia de un esmalte supuestamente debilitado por los cambios gestacionales.

Los vómitos tienen en su composición gran cantidad de ácido clorhídrico, proveniente de las secreciones gástricas, lo que incrementa la acidez, y si además los mecanismos que equilibran el pH salival están deficitarios, se favorece aun más la descalcificación del diente ${ }^{16}$. Un medio ácido es señal inequívoca del fallo de los sistemas amortiguadores del equilibrio ácido-base presentes en la saliva; medio favorable para que se produzca con mayor rapidez el ataque y el debilitamiento del esmalte dentario.

La disminución del pH salival en gestantes, en comparación con no gestantes ha sido reportada por varios autores ${ }^{16}$, aunque hay investigadores que refieren que el contenido ácido del vómito permanece muy poco tiempo en la cavidad bucal como para erosionar el esmalte, y que se requiere este estímulo a repetición; fue constatado que todas las embarazadas que presentaban este factor de riesgo en ambos trimestres, se vieron afectadas por caries dental. Se encontró una tendencia al aumento del $\mathrm{pH}$ en la medida que avanzaba el embarazo, unido a la disminución de la presencia de vómitos en las gestantes. Un estudio similar realizado en Yemen, mostró resultados diferentes en cuanto a la variable vómito, mientras que obtuvo similitud en cuanto al pH salival bajo en las embarazadas estudiadas. ${ }^{14}$ 
Se ha sugerido que un embarazo previo pudiera aumentar el riesgo de padecer enfermedades bucales o padecerlas con mayor severidad. No existe aun una teoría definida al respecto, sin embargo sí se cuenta con algunos elementos que permiten un acercamiento al fenómeno. El sistema inmune materno se suprime en alguna medida para evitar el rechazo madre-feto; la existencia de una disminución en la actividad de las células T y el bloqueo del proceso inicial de activación de linfocitos por la progesterona han sido reportados. Todos estos factores podrían hacer que la embarazada responda de forma ineficaz ante el ataque de la caries dental, y cabe esperar una respuesta intensificada en una segunda exposición al mismo evento. ${ }^{2}$

Durante el periodo gestacional, la composición salival se ve alterada, existe una variación del pH salival y la capacidad buffer 3, en consecuencia, la función para regular los ácidos producidos por las bacterias se ve afectada, ocasionando, en gran medida, un medio bucal favorable para el crecimiento y cambios en las poblaciones bacterianas. ${ }^{17}$

\section{Recomendaciones claves}

$\checkmark$ Para prevenir el desarrollo de caries en la mujer embarazada se debe realizar la evaluación del riesgo de caries a partir del análisis de los factores de riesgo y protectores presentes durante el embarazo.

$\checkmark$ Para disminuir el riesgo de caries en la mujer embarazada se deben instalar hábitos de higiene y alimentación no cariogénica además de las terapias microbiológicas.

$\checkmark$ En mujeres con alto riesgo de caries se debe usar barniz de flúor o enjuagatorios fluorurados como parte de un plan integral de prevención en salud bucal.

$\checkmark$ Cuando la mujer sufra náuseas o vómitos durante el inicio del embarazo se recomienda el uso diario de enjuagatorio de $\mathrm{NaF}$ para favorecer la remineralización del diente y controlar la sensibilidad dentaria asociada.

\section{Conclusiones}

El embarazo genera adaptaciones en la fisiología femenina, que repercute en la salud bucal de la gestante, siendo las afecciones bucales más frecuentes la caries dental, la cual si no es tratada a tiempo puede afectar la salud bucal y general del futuro bebé, de ahí la importancia de tener en cuenta el período prenatal en la prevención de esta enfermedad. 
Los factores de riesgo que se presentan con mayor frecuencia en las embarazadas en el primer trimestre de la gestación son la ingestión de alimentos azucarados y la higiene bucal deficiente. La labor de promoción y prevención por el personal de salud puede, modificar la higiene bucal deficiente en las embarazadas en el tercer trimestre.

\section{Referencias bibliográficas}

1- Noguera Planas, M. Factores de riesgo y caries dental en embarazadas. 2015. [citado 21 junio 2016]. Disponible en: http://www.revista-portalesmedicos.com/revistamedica/riesgo-caries-dental-embarazadas/

2- Díaz Valdés, Liuba; Valle Lizama, Raúl Luis. "Influencia de la salud bucal durante el embarazo en la salud del futuro bebé". Gac Méd Espirit. 2015 [citado 21 junio 2016]; 17(1):111-125. Disponible en: http://scielo.sld.cu/scielo.php?script=sci_arttext\&pid=S1608$89212015000100012 \& \operatorname{lng}=\mathrm{es}$

3- Sposto, M. R.; Onofre, M. A.; Massucato E., M. S.; Soãres, LF. "Atendimento odontológico da paciente gestante: complicações e cuidados a serem odontados”. Odonto 2000. 1997;1(1):20-3.

4- Vera Delgado, M. V.; Martínez Beneyto, Y.; Pérez Lajarín, L.; Fernández Guillart, A.; Maurandi López, A. "Nivel de salud bucal de la mujer embarazada de la comunidad autónoma de la región de Murcia". Odontología Preventiva. 2010;2(1):1-7.

5- Sosa Rosales, M. C. Guías prácticas de estomatología. La Habana: Editorial Ciencias Médicas; 2003. p. 23-72, 195-257, 525-48.

6- Martínez Padilla, S. A. "Morbilidad por caries dental asociada a factores de riesgo biológico en niños". Trabajo para optar por el Título de Especialista de I Grado en Estomatología General Integral. Instituto Superior de Ciencias Médicas "Carlos Juan Finlay", Camagüey. 2002.

7- Jiménez Uley, L. N. “Aplicación de acciones educativas para modificar factores de riesgo de caries dental en niños del Consultorio No. 40”. Trabajo para optar por el Título de Especialista de I Grado en Estomatología General Integral. Instituto Superior de Ciencias Médicas "Carlos J. Finlay", Camagüey. 2005. 
8- Caries y embarazo: la importancia del control y la prevención. 2005 [citado: 13 sep 2016]; 4 p.

Disponible

en:

http://www.buenasalud.com/lib/ShowDoc.cfm?LibDocID=3027\&ReturnCatID=22

9- Rodríguez Chala, H. E.; López Santana, M. "El embarazo. Su relación con la salud bucal". Rev. Cubana Estomatol. 2003 [citado: 13 septiembre 2016]; 40(2): 9 p. Disponible en: http://bvs.sld.cu/revistas/est/vol40_2_03/est09203.htm

10- Pérez Oviedo, Antonio Cecilio; Betancourt Valladares, Miriela; Espeso Nápoles, Nelia; Miranda Naranjo, Madelín; González Barreras, Beatriz. "Caries dental asociada a factores de riesgo durante el embarazo". Rev. Cubana Estomatol. 2011 Jun [citado 13 septiembre 2016]; 48(2):104-112. Disponible en: http://scielo.sld.cu/scielo.php?script=sci_arttext\&pid=S0034$75072011000200002 \& \operatorname{lng}=\mathrm{es}$

11- Carolina De Aguiar, T.; Valsecki Junior, A.; Rocha Corrêa Da Silva, S.; Lopez Rosell, F.; Pereira Da Silva Tagliaferro, E. "Evaluación de factores de riesgo de padecer caries dental en gestantes de Araraquara, Brasil.” Rev. Cubana Estomatol. 2011[citado 13 septiembre 2016];48(4). Disponible en: http://scielo.sld.cu/scielo.php?script=sci_arttext\&pid=S0034-75072011000400005

12- Factores de riesgo. OMS. 2017. [citado 13 septiembre 2016]. Disponible en: http://www.who.int/topics/risk_factors/es/

13- Garbero, I. "Salud oral en embarazadas: conocimientos y actitudes". Acta Odontol. Venez. 2005 [citado: 13 sep 2016]; 43(2): 21 p. Disponible en: http://www.actaodontologica.com/ediciones/2005/2/salud_oral_embarazadas.asp

14- Basterrechéa Milán, M. M.; Alfonso Betancourt, N. M.; Oliva Pérez, M. “Algunos riesgos durante el embarazo en relación con la enfermedad periodontal y la caries dental en Yemen”. Rev. Cubana Estomatol. 2009;46(4):1-15.

15- Duque, J.; Pérez, J. A.; Hidalgo Gato, I. "Caries dental y ecología bucal, aspectos importantes a considerar". Rev. Cubana Estomatol. 2006 [citado: 13 septiembre 2016]; 43(1): 25 p. Disponible en: http://scielo.sld.cu/scielo.php?script=sci_arttext\&pid=S0034$75072006000100007 \& \operatorname{lng}=\mathrm{es} \& n r m=$ iso\&tlng=es 
16- Gonzáles, M.; Montes, O. L.; Jiménez, G. "Cambios en la composición de la saliva de pacientes gestantes y no gestantes”. Perinatol. Reprod. Hum. 2001;15(3):195-201.

17- Chamilco Gamarra, A. Variación del PH y flujo salival durante el periodo gestacional en embarazadas de un servicio asistencial público. 2013. [citado 13 septiembre 2016]. Disponible en: cybertesis.unmsm.edu.pe/bitstream/cybertesis/3372/1/Chamilco_ga.pdf 